\title{
Urgences
}

\section{Jardin d'octobre}

\section{Suzanne Paradis}

Numéro 16, mars 1987

D.G. Jones : d'un texte, d'autres

URI : https://id.erudit.org/iderudit/025402ar

DOI : https://doi.org/10.7202/025402ar

Aller au sommaire du numéro

Éditeur(s)

Urgences

ISSN

0226-9554 (imprimé)

1927-3924 (numérique)

Découvrir la revue

Citer ce document

Paradis, S. (1987). Jardin d'octobre. Urgences, (16), 78-79.

https://doi.org/10.7202/025402ar d'utilisation que vous pouvez consulter en ligne.

https://apropos.erudit.org/fr/usagers/politique-dutilisation/ 


\section{Suzanne Paradis JARDIN D'OCTOBRE}

Sous l'averse, les ombres s'effondrent, les fleurs se meurent

Elles fondent leurs couleurs à celles des feuilles mortes. Ou sont-ce les pierres qui fleurissent

comme l'âme des vieux textes que la voix des absents réveille

De plus en plus ma bouche s'empierre et les os de mes frères ressemblent à des fleurs Vision du ciel peut-être ou magie d'Angkor Wat

Ou suis-je au coeur nocturne d'une cité qui n'existe ni ici ni ailleurs

parmi les hommes? J'y pénètre à tâtons sous la pluie, par la poésie des runes 
Aucune poésie ne se prête à la traduction. On dirait même que chaque poème s'efforce plutôt d'échapper à cette forme de sollicitation. Aussi n'ai-je cherché à traduire que la poignante mélancolie qui m'a saisie à la lecture de "Rock Garden: October». La copie que j'envoie est la septième version et s'écarte considérablement de ma première tentative qui cherchait à "rendre mot pour mot" et à respecter le rythme de l'original. Tout ce que j'ai pu respecter, c'est l'usage des tercets et de certaines rimes ou sonorités assonantes intérieures, pas les mêmes évidemment, mais visant le même effet, à la fois visuel et auditif.

La forme interrogative m'est venue spontanément pour reproduire l'atmosphère de doute et d'illusion créée en anglais par la forme affirmative. Autre effort pour rendre le contenu incernable, plutôt que le contenant. En français - langue de clarté et d'exactitude - la mention de l'heure (sixième tercet) risquait de renvoyer le lecteur à sa montre, bien plus que de le plonger dans le mystère de la nuit. En me relisant, je crois qu'il est évident que le poème de Doug m'a plongée dans l'abîme qui nous guette à la vue des lieux historiques, des tombeaux que les siècles ont construits autour de morts puissants, chargés de nous rappeler la précarité et l'illusoire de la vie. La beauté de Angkor Wat mérite plus que la simple mention qui en est faite; mais telles sont les limites du poème que j'ai ajouté le mot «magie» pour prolonger le charme de l'évocation. Comme le mot "poésie» s'est introduit de lui-même dans le tercet final, après avoir traîné entre les lignes, la seule réponse sans doute à la méditation et à l'interrogation du poète, témoin vivant, médusé par l'étrange spectacle, impuissant à s'en détourner: sa propre défiguration.

P.S. Dommage qu'on n'ait pas pensé à offrir au traducteur un ouvrage de Doug, histoire de le faire mieux connaître, et de mieux rendre son univers. Je suis, hélas, parmi les malheureux qui ne l'ont pas lu. 